\title{
INFLUENCE OF PHOTON ENERGY ON THE EFFICIENCY OF PHOTOCHEMOTHERAPY
}

\author{
M. P. Samtsov, ${ }^{\text {b }}$ E. S. Voropay, ${ }^{a}$ K. N. Kaplevsky, ${ }^{a}$ \\ D. G. Melnikau, ${ }^{\mathrm{a}}$ L. S. Lyashenko, ${ }^{\mathrm{a}}$ and Yu. P. Istomin ${ }^{\mathrm{c}}$
}

UDC 535.37+535.34:541.14

It is found that when indotricarbocyanine dye in HeLa cells is exposed to photons with different energies the efficiency of cell damage is wavelength independent provided the photosensitizer absorbs the same number of photons per unit time. In vivo animal experiments with two strains of tumor show that when the wavelength of the irradiating light is increased $(668,740$, and $780 \mathrm{~nm})$ and the number of photons absorbed per unit time per unit volume of the tumors is held constant, the damage depth increases by a factor of 1.5 and 3 , respectively. The observed changes are related both to differences in the in vivo tissue optical transmission with increasing wavelength and an increased local concentration of oxygen owing to photodissociation of oxyhemoglobin.

Key words: indotricarbocyanine dyes, in vivo, efficiency of photochemotherapy, wavelength of light

Introduction. One of the most important parameters in the development of a new generation of sensitizers for photochemotherapy is their ability to be activated by light with wavelengths lying within the transparency region for biological tissues. The absorption bands for these compounds must lie within 700-800 nm [1-6], i.e., in the near IR. It has been shown $[7,8]$ that, even within the visible, moving to wavelengths with higher transmission in tissues leads to an increase in the depth to which tumors are destroyed. In the meantime, no data comparing the efficiency of photochemotherapy with light in the visible and near IR ranges have been published. This kind of study requires photosensitizers with a sufficiently wide absorption spectrum. The main absorption band of the tricarbocyanine dyes lies in the 600-800 nm range $[9,10]$ so that the degree of damage to tumors within this spectral range can be compared.

Materials and Methods. Tricarbocyanine dye synthesized at the spectroscopy laboratory of the A. N. Sevchenko Institute of Applied Physical Problems [11] was used as a photosensitizer. Studies were carried out on a monolayer of HeLa tumor cells (planocellular cancer of the human uterine cervix) grown in a 199 nutritive medium supplemented with $10 \%$ calf blood serum and $100 \mathrm{mg} / \mathrm{ml}$ kanamycin. On completion of the light irradiation the flasks were kept in the dark for $20 \mathrm{~h}$ with thermostatic regulation at $37^{\circ} \mathrm{C}$. Then the monolayer of cells was processed by a $0.02 \%$ Versene solution and the number of cells was counted using a Goryaev camera. The fraction of living cells in the experimental groups was determined in relation to the control. Three flasks with cells were used for each point. Solid interwoven tumors of white non-breed rats, sarcoma M-1 (Sa M-1) and alveolar liver cancer (RS-1), were used as experimental in vivo model systems. The studies were carried out 9-10 days after interweaving of the Sa M-1 and 1 month for the RS-1. 3-5 rats were used in each control and experimental group. The efficiency of the photointeraction was evaluated in terms of the depth of damage (necrosis) of the tumor tissue using vital coloring.

Semiconductor lasers with $\lambda=740$ and $668 \mathrm{~nm}$ were used to irradiate the flasks with the cells and tumor tissues of the animals. The source for $\lambda=780 \mathrm{~nm}$ was a light emitting diode. The power of the light incident on the samples was determined using an LM-2 power meter. The absorption spectra were recorded using a Solar PV 1251A spectrophotometer. The fluorescence of the dye solutions was studied on a Fluorolog spectrofluorimeter. The fluorescence spectra of the dye in vivo were recorded using a spectrophotometer system developed at the Sevchenko Institute

*To whom correspondence should be addressed.

${ }^{\mathrm{a}}$ Belarus State University, Minsk; e-mail: voropay@bsu.by; ${ }^{\mathrm{b}}$ A. N. Sevchenko Institute of Applied Physical Problems, 7 Kurchatov Str., Minsk, 220064, Belarus; e-mail: samtsov@bsu.by; ${ }^{\mathrm{c}}$ N. N. Aleksandrov Institute of Oncology and Radiology, Minsk, Belarus. Translated from Zhurnal Prikladnoi Spektroskopii, Vol. 76, No. 4, pp. 576-582, July-August, 2009. Original article submitted May 20, 2009. 
[12]. The exciting radiation $(\lambda=683 \mathrm{~nm})$ was delivered to the sample and the fluorescence light was collected and sent to the spectrophotometer system using a light guide.

Results and Discussion. The photoactivity of tricarbocyanine dye was studied in experiments in vitro (HeLa cells) and in vivo on interwoven Sa M-1 and RS-1 sarcoma tumors. If no photosensitizer is introduced, the HeLa cells essentially do not absorb in the $600-900 \mathrm{~nm}$ range; the optical density of a suspension containing $2 \cdot 10^{6}$ cells $/ \mathrm{cm}^{3}$ is less than $D<0.006$. The cell culture is a medium in which there is no difference in the transmission for light at the wavelengths of the sources used here. Thus, a study of the photoactivity of the dye under these conditions can be used to establish the existence or absence of specificity in its behavior when excited by light with different wavelengths.

A comparison of the efficiency of photochemotherapy using light with different wavelengths must take into account the fact that the degree of damage to cells depends substantially on the power density (flux) of the incident radiation [13, 14]. Photodynamic therapy is based on photochemical reactions whose rate depends on the properties of the photosensitizer and the parameters of the light, as well as on the presence of oxygen in the medium. This last requirement arises from the oxygen demand during a photodynamic therapy session, which, if a sufficiently high luminous flux is used, leads to a significant reduction in the level of oxygenation of the tumor cells and, therefore, to a reduction in the efficiency with which they are destroyed [15-17]. Thus, the comparison of the efficiency of light induced damage to tumor cells using radiation at $\lambda=668,740$, and $780 \mathrm{~nm}$ was undertaken subject to a number of conditions being met. First of all, the concentration of the sensitizer was kept the same in the tumor tissue and cells during the measurements. In order to establish the time interval over which the photosensitizer concentration is stable, the time dependence of the accumulation of the dye in tumor cells of the HeLa culture was studied (Fig. 1). The amount of the dyes in the cells as a function of the time the photosensitizer was retained in the culture medium was determined by extracting photosensitizer from the cells using butanol-1 and then taking its absorption spectrum. The concentration of photosensitizer entering a cell was calculated from the known molar extinction coefficient of the dye in butanol-1. Based on the data on the time dependence of the buildup of dye in the tumor cells when the preparation was fed into the culture medium it was found that for incubation times $t \leq 1 \mathrm{~h}$ the amount of dye in the HeLa cells increases, and then stays at a fixed level for $3 \mathrm{~h}$. Based on this, in the subsequent studies of the culture medium the incubation time for the preparation was set at $2 \mathrm{~h}$.

In order to ensure the same rate of oxygen and dye consumption during the photointeraction process, at each wavelength conditions were set up so that the same number of photons were absorbed by the photosensitizer in the biological structures per unit time. This was done by selecting the flux incident on the sample for each source. The ratio of the energy flux was determined from the absorption spectrum of polymethene dye in HeLa cells (Fig. 2) at $\lambda=668,740$, and $780 \mathrm{~nm}$ in accordance with values of $(1-T)$ proportional to the amount of photons absorbed by the photosensitizer, where $T$ is the transmission of the sample. These data were used to calculate by what factor it is necessary to increase the flux of the incident light corresponding to the edges of the spectrum compared to the maximum absorption. Thus, in order to ensure that the same number of photons is absorbed by the photosensitizer per unit time, at $\lambda=668 \mathrm{~nm} 2.8$ times, and at $\lambda=780 \mathrm{~nm} 2.3$ times, the flux at $\lambda=740 \mathrm{~nm}$ was used (taking into account the differences in the photon energies for the light sources that were used). Under these conditions, photoexcitation was carried out for the same length of time for each source; this provided an equally efficient exposure dose.

Photoexcitation of HeLa cells without the photosensitizer or after incubation of cells with photosensitizer, but without photoexcitation, had no effect on the amount of cells in the flasks. At $\lambda=740 \mathrm{~nm}$ the photoexcitation power density was $I=10,20,25$, and $30 \mathrm{~mW} / \mathrm{cm}^{2}$, while the luminous energy dose was $10 \mathrm{~J} / \mathrm{cm}^{2}$. For convenience in analyzing the results, the data for the effective power densities at $\lambda=668$ and $780 \mathrm{~nm}$ are shown in Fig. 3. It can be seen that under these exposure conditions the fraction of destroyed cells is essentially the same for all these wavelengths. For fluxes $I=10$ and $20 \mathrm{~mW} / \mathrm{cm}^{2}$ the fraction of destroyed cells exceeds $90 \%$, while for $I=25$ and 30 $\mathrm{mW} / \mathrm{cm}^{2}$ a reduction in the efficiency of cell destruction is observed. Most likely the drop in the phototoxicity of the dye in the cells with increasing flux is caused by a reduction in the concentration of oxygen and by photodecomposition of the photosensitizer [15-17].

These data indicate that the photoactivation efficiency for destruction of cancer cells when the number of photons absorbed per unit time by the photosensitizer is kept constant is the same for each of the three wavelengths. 


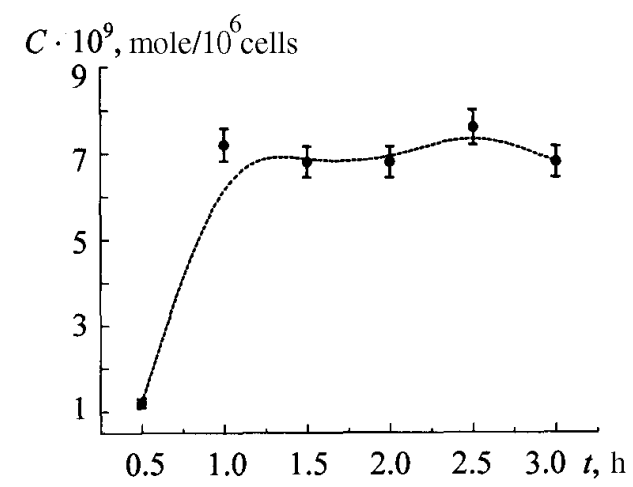

Fig. 1. The time evolution of the concentration of the photosensitizer in tumor cells of an HeLa culture.

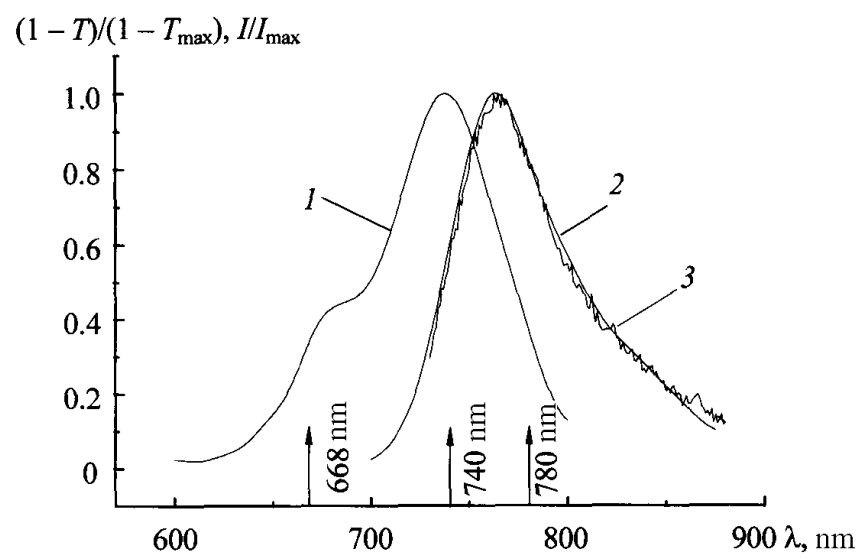

Fig. 2. Absorption (1) and fluorescence $(2,3)$ spectra of the photosensitizer in HeLa cells $(1,3)$ and in vivo taking absorption in the biological tissue into account (2).

Thus, for a transparent biological medium there are no differences in the activity of the photosensitizer for exposure to radiation within the confines of the principal absorption band of the photosensitizer.

In the in vivo experiments, the efficiency of the photochemotherapeutic action of the dye was estimated in terms of the depth of damage to solid tumors of laboratory animals. To determine the time over which the dye concentration in the tumor tissue is constant, a study was made of the time evolution of the dye buildup in the tissues after intravenous delivery to the animals. The amount of dye in the tumor tissue in vivo was determined from the intensity of the fluorescence spectra of the photosensitizer. In order to confirm the correspondence between the fluorescence intensity and the dye concentration in the living organism, studies were done with several concentrations of the photosensitizer given to the animals. It was found that the intensity of the dye fluorescence is directly proportional to the concentration of the photosensitizer given to an animal (Fig. 4).

Based on the in vivo pharmacokinetics for the different types of tumors, the optimum time for beginning a photochemotherapy session after introduction of the photosensitizer was found to be $3 \mathrm{~h}$. To choose the optimum luminous energy dose a study of the M-1 rate sarcoma strain was made with irradiation at doses of 100, 160, 240, and $320 \mathrm{~J} / \mathrm{cm}^{2}$ by light at $\lambda=740 \mathrm{~nm}$ and with a sensitizer concentration of $5 \mathrm{mg} / \mathrm{kg}$. An analysis of sections of the tumors showed that for doses of 100 and $160 \mathrm{~J} / \mathrm{cm}^{2}$ necrosis boundaries were clearly visible in a histotopographic section of Sa M-1 with a shape corresponding to the light beam and depths of $12 \pm 2$ and $15 \pm 2 \mathrm{~mm}$. For a luminous 


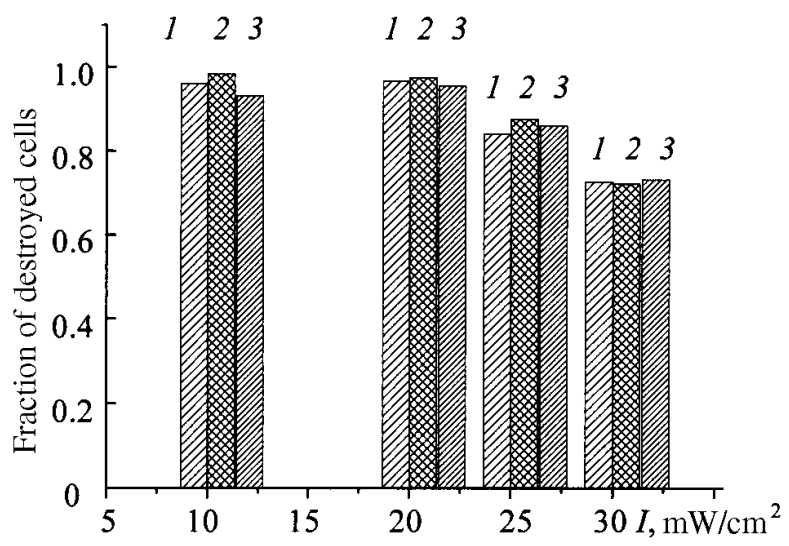

Fig. 3. The fraction of destroyed HeLa cells as a function of the photoexcitation flux for a photosensitizer concentration of $5 \mu \mathrm{g} / \mathrm{ml}$ in the cells and an effective luminous energy dose of $10 \mathrm{~J} / \mathrm{cm}^{2}$ at $\lambda=668$ (1), 740 (2), and 780 nm (3).

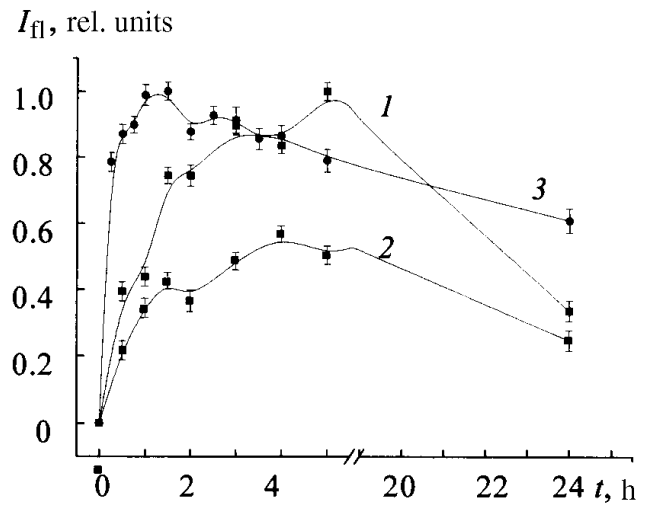

Fig. 4. Time variation of the buildup in vivo of the photosensitizer in M-1 sarcoma tumor for photosensitizer concentrations of 2.5 (1) and $1.25 \mathrm{mg} / \mathrm{kg}(2)$, and in RS-1 tumor for a concentration of $5 \mathrm{mg} / \mathrm{kg}(3)$.

dose of $240 \mathrm{~J} / \mathrm{cm}^{2}$, the damage to the tumor node reached its boundaries at a depth $(>20 \mathrm{~mm})$ and for $320 \mathrm{~J} / \mathrm{cm}^{2}$ complete necrosis of the entire tumor node was observed. These results show that it is appropriate to compare the efficiency of destruction of tumor nodes for a luminous exposure energy dose at $\lambda=740 \mathrm{~nm}$ within a range of 100 $160 \mathrm{~J} / \mathrm{cm}^{2}$.

It has been shown [18] that the half width and position of the maximum in the fluorescence spectrum of polymethene dye are the same (Fig. 2) in HeLa cells and in a living organism (taking the absorption of blood components into account). Because the polarity of the medium has a significant influence on the spectral and luminescence characteristics of the class of compounds [19] under study, this agreement suggests identical surroundings for the photosensitizer molecules in vivo and in vitro; thus, the absorption spectra of the photosensitizer for these systems are the same. Hence, as in the case of the HeLa cell culture, the amount of photons absorbed by the photosensitizer per unit volume of tumor in vivo per unit time at $\lambda=668 \mathrm{~nm}$ was kept the same by using radiation with a flux 2.8 greater and at $\lambda=780 \mathrm{~nm}, 2.3$ times greater, than at $\lambda=740 \mathrm{~nm}$. Under these conditions an effective exposure dose ensur- 
TABLE 1. Depth of damage in solid Sa M-1 and RS-1 rat tumors under photochemotherapy

\begin{tabular}{||c|c|c|c|c|c|c||}
\hline Strain & $\begin{array}{c}\text { Photosensitizer } \\
\text { concentration, } \\
\mathrm{mg} / \mathrm{kg}\end{array}$ & $\begin{array}{c}\text { Wavelength, } \\
\mathrm{nm}\end{array}$ & $\begin{array}{c}\text { Energy flux, } \\
\mathrm{W} / \mathrm{cm}^{2}\end{array}$ & $\begin{array}{c}\text { Effective } \\
\text { energy dose, } \\
\mathrm{J}^{2} \mathrm{~cm}^{2}\end{array}$ & $\begin{array}{c}\text { Actual energy } \\
\text { dose, J/cm }\end{array}$ & $\begin{array}{c}\text { Mean depth of } \\
\text { necroses, } \mathrm{mm}\end{array}$ \\
\hline Sa M-1 & 2 & 780 & 0.45 & 130 & 360 & $18 \pm 2$ \\
Sa M-1 & 2 & 740 & 0.2 & 130 & 130 & $12 \pm 2$ \\
Sa M-1 & 2 & 668 & 0.6 & 130 & 364 & $8 \pm 2$ \\
PS-1 & 5 & 740 & 0.25 & 160 & 160 & $19 \pm 2$ \\
PS-1 & 5 & 668 & 0.7 & 160 & 448 & $13 \pm 2$ \\
\hline
\end{tabular}

ing absorption of the same number of photons per unit tumor volume by the photosensitizer was attained for each source over the same exposure time.

Table 1 lists the results of the effect of the different light sources on the RS-1 tumor strain for a dye concentration of $5 \mathrm{mg} / \mathrm{kg}$ and on the Sa M-1 strain for a dye concentration of $2 \mathrm{mg} / \mathrm{kg}$. It can be seen here that the average depth of destruction of the interwoven Sa M-1 rat tumors at $9780 \mathrm{~nm}$ is 1.5 times greater than for $\lambda=740 \mathrm{~nm}$ and 3 times greater than for $\lambda=668 \mathrm{~nm}$; that is, within the spectral range studied here the depth of damage to the tumor tissue increases with the wavelength of the light source.

The ratio of the mean depths of necroses for the two strains of tumor studied here for light at 740 and 668 $\mathrm{nm}$ are essentially the same (1.46 and 1.5). It should be noted that this agreement has been observed for the RS-1 and Sa M-1 strains, which differ in their rates of growth, microcirculation alveus, and histological structure, while the photosensitizer concentrations differ by a factor of 2.5 , the luminous energy doses are 160 and $130 \mathrm{~J} / \mathrm{cm}^{2}$, and the laser energy fluxes are different. The increase in the depth of necrosis when light with $\lambda=740 \mathrm{~nm}$ is used instead of $\lambda=669 \mathrm{~nm}$ corresponds to the increase in an optical parameter - the transmission of light by the tissues - and therefore, an increase in the depth to which the light can penetrate into the tissue on moving into the IR [20, 21]. The transmission of biological tissue at $668 \mathrm{~nm}$ is $1.2-1.5$ times greater than at $740 \mathrm{~nm}$ [20-23]. The absorption coefficients of biological tissues at $\lambda=780$ and $740 \mathrm{~nm}$ are fairly close [20-23], and at the same time, a significant (up to a factor of 1.5) difference in the depth of necrosis for irradiation with light at $\lambda=780$ and $740 \mathrm{~nm}$ was observed. Hence, the differences in the depth of damage to tumors during irradiation by light with different wavelengths is not determined solely by differences in the transmission by the tissues.

When the same number of photons per unit time is absorbed by the photosensitizer per unit volume for light sources at 668 and $780 \mathrm{~nm}$, the actual incident irradiation dose is higher than for $\lambda=740 \mathrm{~nm}$. This causes heating of the tissues and leads to an increase in the rate of blood flow; this facilitates the arrival of new portions of sensitizer in the irradiated section of the tumor and, in principle, can influence the damage efficiency. However, during irradiation at $668 \mathrm{~nm}$, the depth of damage in the tumor nodes is shallower than at $740 \mathrm{~nm}$, although the actual luminous exposure dose for the $668 \mathrm{~nm}$ source is greater by more than a factor of two. Therefore, in this case the higher luminous energy flux and dose are not the factors determining the increase in the depth of necrosis.

The most important factor in the increased efficiency of damage to the tumor tissues with increasing interaction wavelength is the increased yield of free oxygen in the tissue owing to photodissociation of oxyhemoglobin molecules in blood [24-26]. The quantum efficiency of the photodissociation process is several percent and increases with increasing wavelength $[25,27]$. A calculated spectrum of the action of laser light on the photodissociation capacity of oxyhemoglobin has been published [25]. This spectrum implies that the photodissociation efficiency of hemoglobin complexes in blood vessels at $\lambda=780 \mathrm{~nm}$ is almost a factor of three times greater than for $740 \mathrm{~nm}$ and more than a factor of 10 times greater than for $668 \mathrm{~nm}$. It has been found $[28,29]$ that during irradiation by light from two sources with different wavelengths, one of which coincides with the absorption peak of the photosensitizer while the second coincides with the same for hemoglobin, the efficiency of photodynamic therapy increases. The observed effect was qualitatively explained in terms of the photodissociation of oxyhemoglobin [28]. In our case, on going to irradiation at $780 \mathrm{~nm}$ the amount of oxygen in the irradiated tumor tissue also increases because of a local increase in the tissue temperature, which enhances the photodissociation quantum yield for hemoglobin [30]. Here the increased blood 
flow ensures that a higher concentration of photosensitizer is maintained in the tumor. All of these factors increase the efficiency of photodynamic therapy.

Conclusion. Under conditions such that the photosensitizer absorbs an equal amount of photons per unit time, the photocytotoxicity of tricarbocyanine dye in a HeLa cancer cell culture is independent of the wavelength of the irradiating light. In in vivo experiments with animals, the average depth of damage to interwoven rat tumors of strains RS-1 and Sa M-1 increased with increasing wavelength of the exciting light when the number of photons absorbed by the photosensitizer per unit time per unit tumor volume was kept fixed. The differences in the depth of damage in tumors for sources with different wavelengths are determined both by differences in the optical transmission of the tissues and by differences in the photodissociation efficiency of hemoglobin in blood vessels.

Acknowledgment. This work was partially supported by the Belarus Republic Foundation for Basic Research (grant No. F08-199).

\section{REFERENCES}

1. T. J. Dougherty, C. J. Gomer, B. W. Henderson, G. Jori, D. Kessel, M. Korbelik, J. Moan, and Q. Peng, J. Natl. Cancer Inst., 90, 889-905 (1998).

2. R. Hsi, D. Rosental, and E. Glatstein, Drugs, 57, 725-734 (1999).

3. E. S. Voropay, M. P. Samtsov, A. P. Lugovskiy, E. N. Aleksandrova, V. N. Chalov, and E. A. Zhavrid, and Y. P. Istomin, Proc. SPIE, 4749, 221-227 (2002).

4. A. F. Mironov, M. A. Grin, A. G. Tsiprovskii, A. V. Segenevich, D. V. Dzardanov, K. V. Golovin, A. A. Tsygankov, and Y. K. Shim, Bioorg. Chem., 29, No. 2, 190-197 (2003).

5. Y. Chen, A. Graham, W. Potter, J. Morgan, L. Vaughan, D. Bellnier, B. Henderson, A. Oseroff, T. Dougherty, and R. Pandey, J. Med. Chem., 45, No. 2, 255-258 (2002).

6. M. Oertel, S. Schastak, A. Tannapfel, R. Hermann, U. Sack, J. Mossner, and F. Berr, J. Photochem. Photobiol. B, 71, Nos. 1-3, 1-10 (2003).

7. M. Blank, G. Kostenich, G. Lavie, S. Kimel, Y. Keisari, and A. Orenstein, J. Photochem. Photobiol. B, 76, No. 3, 335-340 (2002).

8. L. Lee, C. Whitehurst, M. Pantelides, and J. Moore, J. Photochem. Photobiol., 62, No. 5, 882-886 (1995).

9. A. Oseroff, G. Ara, D. Ohuoha, J. Aprille, J. Bommer, M. Yarmush, J. Foley, and L. Cincotta, J. Photochem. Photobiol., 46, 83-96 (1987).

10. G. S. Lipshutz, D. J. Castro, R. E. Saxton R. P. Haugland, and J. Soudant, Laryngoscope, 104, 996-1002 (1994).

11. Y. P. Istomin, E. N. Alexandrova, V. N. Chalov, E. A. Zhavrid, E. S. Voropay, M. P. Samtsov, A. P. Lugovskiy, A. A. Lugovskiy, and I. S. Mikhalovsky, Exper. Oncology, 26, No. 3, 226-231 (2004).

12. E. S. Voropai, M. P. Samtsov, I. M. Gulis, D. V. Glushkov, K. N. Kaplevskii, A. E. Rad'ko, K. A. Shevchenko, et al., in: E. S. Voropai, ed., Spectral Appratus for Analytic Applications. Promising Developments [in Russian], Bel. gos. un-t, Minsk (2005), pp. 5-9.

13. S. Coutier, S. Mitra, L. Bezdetnaya, R. Parache, I. Georgakoudi, and F. Guillemin, J. Photochem. Photobiol., 73, (3), 297-303 (2001).

14. H. Pass, J. Natl. Cancer Inst., 85, 443-456 (1993).

15. E. F. Stranadko, Ros. Onkolog. Zh., No. 4, 52-56 (2000).

16. T. Hasan and J. Parrish, Cancer Medicine, (1997), pp. 739-751

17. P. Vaupel, O. Thews, D. Kelleher, and M. Hoeckel, Strahlenther. Onkol., 174, No. 4, 6-12 (1998).

18. M. P. Samtsov, E. S. Voropay, D. G. Melnikov, and K. N. Kaplevsky, Roc. SPIE, 6733, 67331C-1-67331C-8 (2007).

19. E. S. Voropai, M. P. Samtsov, K. N. Kaplevskii, A. A. Lugovskii, and E. N. Aleksandrova, Zh. Prikl. Spektr., 71, No. 2, 166-172 (2004).

20. V. B. Loshenov, V. I. Konov, and A. M. Prokhorov, Las. Physics, 10, No. 6, 1188-1207 (2000).

21. P. Taroni, A. Pifferi, A. Torricelli, and D. Comelli, Photochem. Photobiol. Sci., 2, (2003) 124-129

22. A. Ballangrud, O. Barajas. A. Georgousis, G. Miller, R. Moore, and M. Phee, Lasers in Surgery and Medicine, 21, No. 2, 124-133 (1997). 
23. R. Weissleder and V. Ntziachristos, Nature Medicine, 9, No. 1, 123-128 (2003).

24. M. M. Asimov, R. M. Asimov, and A. N. Rubinov, Zh. Prikl. Spektr., 65, No. 6, 877-880 (1998).

25. M. M. Asimov, R. M. Asimov, A. N. Rubinov, S. A. Mamilov, Yu. S. Plaksii, and S. S. Es'man, Laser-induced oxygenation of tissues and stimulated aerobic cell metabolism, Preprint, Inst. of Physics of the National Acad. of Sci. of Belarus, Minsk, No. 746 (2008).

26. G. A. Zalesskaya and V. S. Ulashchik, Zh. Prikl. Spektrosk., 76, No. 1, $51-75$ (2009).

27. B. M. Dzhagarov, V. S. Chirvonyi, and G. P. Gurinovich, in: V. S. Letokhov, ed., Picosecond Spectroscopy and Photochemistry of Biological Molecules [in Russian], Mir, Moscow (1987), p. 212.

28. B. M. Dzhagarov, É. A. Zhavrid, Yu. P. Istomin, and V. N. Chalov, Zh. Prikl. Spektrosk., 68, No. 2, 151-153, (2001).

29. B. M. Dzhagarov, S. A. Bizyuk, M. V. Parkhots, É. A. Zhavrid, and Yu. P. Istomin, in: Abstracts from the International Conf. on Laser-optical Technology in Biology and Medicine, October 14-15, 2004, Inst. of Physics of the National Acad. of Sci. of Belarus, Minsk (2004), pp. 163-168.

30. M. M. Asimov, R. M. Asimov, and A. N. Rubinov, Lazern. Meditsina, 11, 53-59 (2007). 